\title{
Prognostic typing in breast cancer ${ }^{1}$
}

\section{Further investigation of a necropsy series compared with recent surgical specimens}

\author{
B. O. MAEHLE AND F. HARTVEIT \\ From the Gade Institute, Department of Pathology, University of Bergen, Norway
}

SYNOPSIS A comparison of material from necropsy and surgical series has shown that breast carcinit oma of cytological types II and III are rare. The majority of cases are of type I. Of the latter, tumours in TNM stage I were not found in the necropsy series, while infiltrating duct carcinomas of type $P_{1}$ TNM stage II were also absent. This suggests that the possibility of surgical cure may be better inp type I duct carcinomas in stage II than with other histological types. Prolonged survival in contras to surgical cure was related to type III tumours irrespective of TNM stage.

The question of prognosis in breast cancer is a vexed one that tends to be complicated by two different points of view. In one, the surgical approach, the question, What is the prognosis, implies what is the chance that radical surgery will cure? The second is the biological approach. Here the question implies, What is the natural history of this particular tumour? The pathologist must try to answer both forms of the question, in spite of the fact that the surgeon consistently 'ruins' his basic material by removing tumours successfully. In the absence of tumour there can be no prognosis in the biological sense.

However, as Collins (1956) has pointed out, patients who die of breast cancer, regardless of treatment, probably demonstrate the biological potential, or natural history, of their tumour. Survival time curves from such cases are indeed remarkably similar to those from untreated series in the literature (Daland, 1927; Bloom, 1968). If this view is accepted the question can be broken down into its two parts: first, Which patients are cured by radical surgery, ie, removal of the breast and axillary nodes, and secondly, Which patients die of breast cancer, ie, have tumours that complete their life history regardless of treatment.

The following paper describes an analysis of this type.

${ }^{1}$ The staging is that of the International Union against Cancer called the TNM system ( $\mathrm{T}$, the tumour; $\mathrm{N}$, the regional lymph nodes; $\mathbf{M}$, distant metastases). The Union recommends four stages from combinations of the several categories of $T, N$, and $M$.

Received for publication 16 July 1973.

\section{Material and Methods}

The necropsy series has already been repore (Harveit, 1971). It consisted of patients coming necropsy at this Institute between the years 1963 1970. In all cases the cause of death had been reo corded as carcinoma of the breast and in all case 8 material from the primary tumour was also available for classification. In the 87 cases used in the presen $\vec{E}$ study sufficient information was available from the pathology reports, the surgical specimens and/o case reports for TNM staging (Harmer, Denoix and Hamperl, 1970), ie, two cases from the origina尔 series were omitted on these grounds.

The surgical series consisted of 147 primar infiltrating breast carcinomas in patients wh. presented at this Institute between March 1971 an 1972. In all sufficient information was available fob TNM staging.

The age of the patients at the time of removal of the primary tumours was recorded in both series and the age at death in the necropsy series.

One section from each primary tumour, formalinis fixed, paraffin-embedded, and stained with haemaro toxylin and eosin was examined. In the surgicaus series the histological classification was recorded twice by one of us (H.) at an interval of five week the order of the specimens being unknown. There after the cytological type was recorded independently by each of us. In the necropsy series the histologica: classification was recorded twice and the cytologici⿱ type once by one of us (H.). 


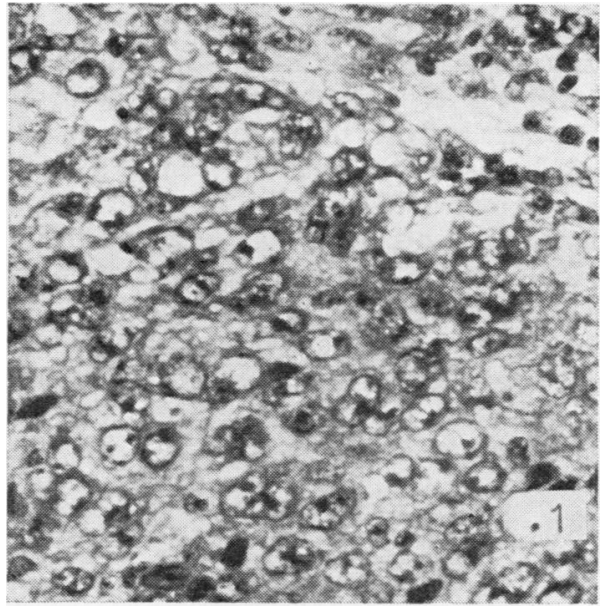

Fig 1 Breast carcinoma of type I. Note lack of definition of cell borders, crowded lobulated nuclei, high nucleocytoplasmic ratio. $H$ and $E \times 280$.

\section{CYTOLOGICAL TYPING FROM HISTOLOGICAL} MATERIAL

The method has been described in detail (Hartveit, 1971). Groups of tumour cells, either 'in situ' or in tissue spaces were used for classification. In type I the tumour cell groups have indistinct cell borders, the nuclei are crowded in irregular groups, the nuclear membrane has an irregular lobular outline, and the amount of cytoplasm per cell is difficult to define (fig 1). Type III shows the opposite featuresdistinct cell borders, abundant cytoplasm, and smooth nuclear membrane (fig 2). Type II shows a mixture of these features, for example, clearly defined cell borders but an irregular, lobulated nuclear outline.

\section{HISTOLOGICAL CLASSIFICATION}

All were infiltrating carcinomas. They were further classified as follows:

\section{Scirrhous}

In the presence of a marked connective tissue reaction when the infiltrating tumour cells showed no attempt at tubular arrangement.

\section{Adenocarcinoma}

When the tumour cells grew with an obvious tubular arrangement.

\section{Duct}

When tumour cell growth was present in the major or minor ducts.

\section{Medullary}

When the tumour cells grew in solid cords several

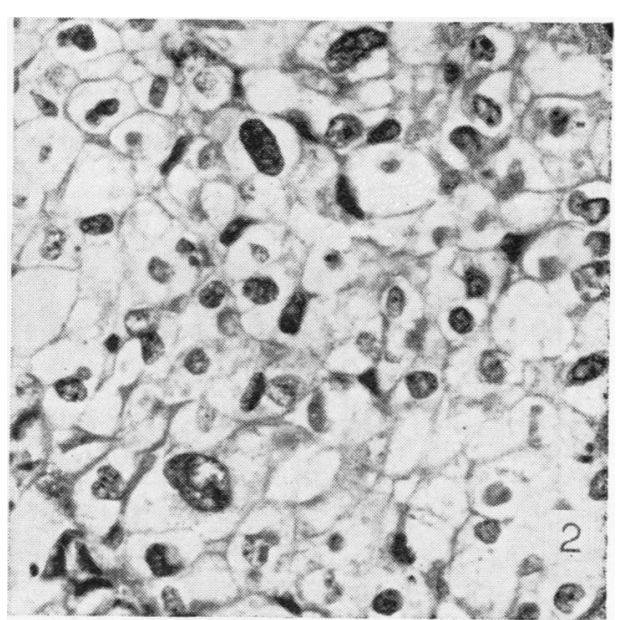

Fig 2 Breast carcinoma of type III. Note well defined cell borders, smooth nuclear outline, and abundant cytoplasm. $H$ and $E \times 280$.

cells thick with connective tissue stroma between the individual cords.

\section{Papillary}

When finer tumour cell cords were present, not individualized by connective tissue stroma.

\section{Colloid}

When groups of tumour cells surrounded by colloid material predominated.

\section{Results}

The surgical series is represented in fig 3 as a frequency polygon which gives the percentage incidence of breast carcinoma in this series related to the patient's age when the tumour presented. Superimposed on the polygon is a line diagram that represents the number of new cases of breast cancers in Norway as a whole in 1962-66 (Ringertz, 1971). The two populations are similar in age distribution, the only striking difference being possible underrepresentation in the present surgical series in the 45-50-year age group, which cannot be explained on present data.

The necropsy series is represented in a similar manner in fig 4 that shows the age at which the tumours presented, again with the 1962-66 material superimposed as a line diagram. Here we have overrepresentation of the 35-45-year groups in the necropsy series.

The necropsy series is shown again in fig 5 which gives the age of the patients at death. Superimposed is a line diagram representing the age at death for 


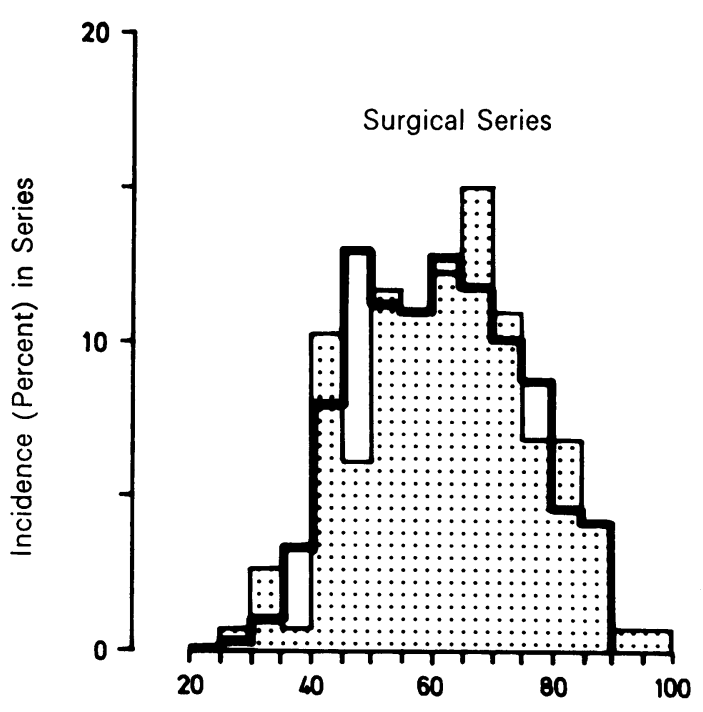

Age (yr) When Tumour Presented

Fig 3 The percentage incidence of breast carcinoma in the surgical series related to the patient's age when the tumour presented. Superimposed is a line diagram representing the number of new cases of breast cancer in Norway as a whole in 1962-66 (Ringertz, 1971).

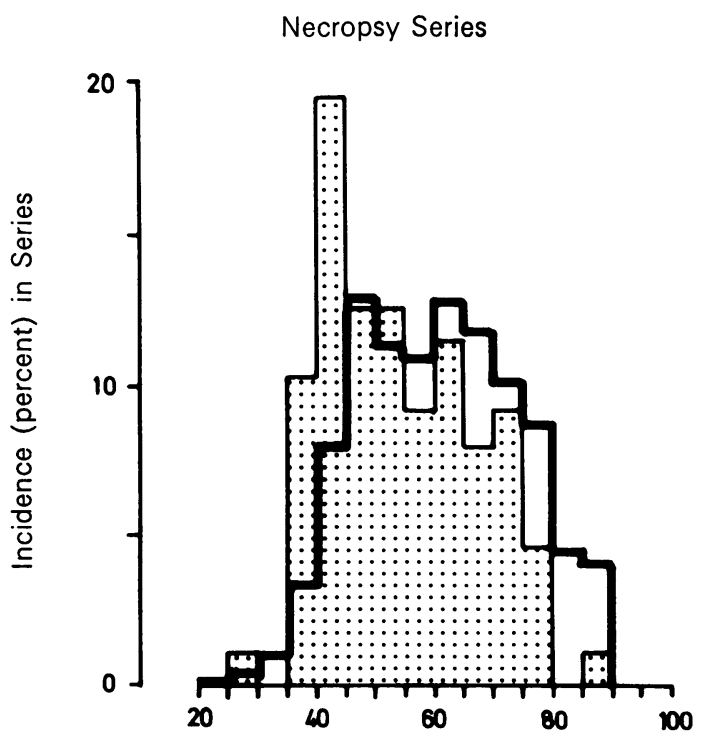

Age (yr) When Tumour Presented

Fig 4 The percentage incidence of breast carcinoma in the necropsy series related to the age when the tumour presented, with the number of new cases of breast cancer for Norway as a whole in 1962-66 superimposed (Ringertz, 1971). all patients dying of breast cancer in Norway in $19699^{\circ}$ (Norway Central Bureau of Statistics, Oslo 1969) Comparison here shows that there is overrepresent - ation in the present series in 35-50-year groups $\overrightarrow{=}$ and possible underrepresentation from 55 to 75 years-

The overrepresentation may be due to selection of younger patients dying of cancer for treatmenten in hospital, while the underrepresentation couldo reflect the more frequent use of a previously established diagnosis in death certification in older women ${ }^{\circ}$ when necropsy has not been carried out (see Prutting, $\vec{\circ}$ 1972).

The difference in mean age when the tumour $\vec{\omega}$

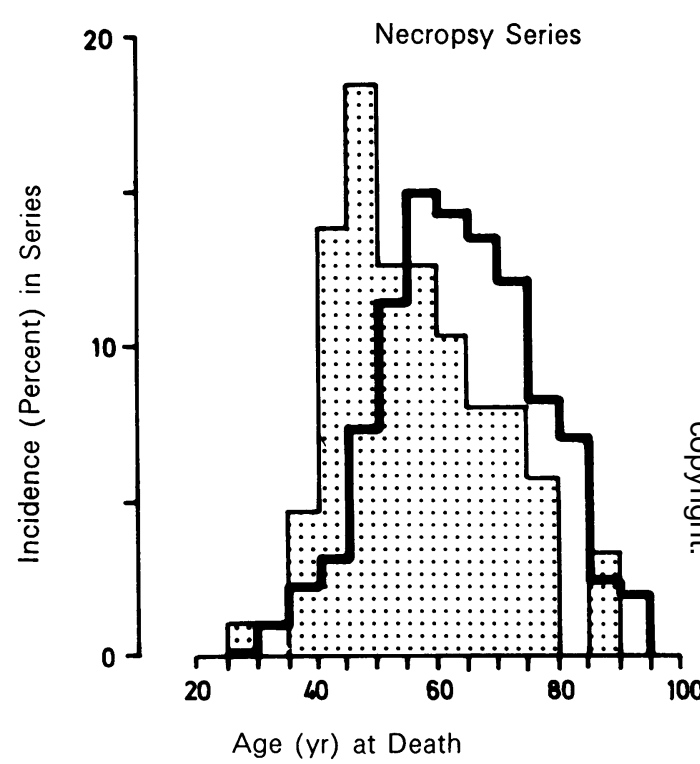

Fig 5 The age at death of the patients in the necropsy series. A line diagram representing the age at death for all patients dying of breast cancer in Norway in 1969 is superimposed (Central Bureau of Statistics, Oslo).

presented between the necropsy and surgical $\frac{}{2}$ series is statistically significant $(0.01>P>0.001), D$ being $53.4 \pm 12.9$ and $62.2 \pm 13.8$ years respectively. This does not necessarily indicate that tumours in ${ }_{\sigma}$ older women are less dangerous but that these patients may die of other causes before they can be killed by their tumours.

The relationship between TNM staging and age when the tumour presented is shown for bothe series in fig 6 which records the number of cases in $\mathbb{\Phi}$ each stage. An excess of stage I and II tumours ${ }^{+}$ in the surgical series is evident on inspection. The $\frac{T}{T}$ percentage distribution of these cases related to $\frac{\text { ? }}{\mathbb{D}}$ TNM stage is given in table I. From this it appears $\frac{\mathrm{Q}}{\mathbb{D}}$ 


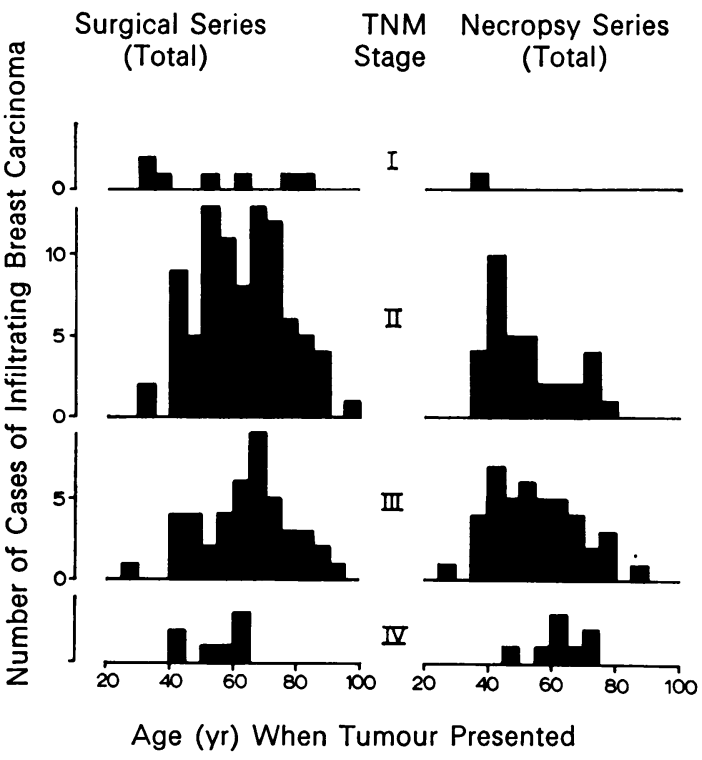

Fig 6 The relationship between TNM stage and age when the tumour presented in both the surgical and necropsy series.

\begin{tabular}{lcc}
\hline Stage & \multicolumn{2}{l}{ Series } \\
\cline { 2 - 3 } & Surgical & Necropsy \\
\hline I & 5 & 1 \\
II & 60 & 40 \\
III & 30 & 50 \\
& 5 & 9 \\
\hline
\end{tabular}

Table I Percentage distribution of tumours of different TNM stages in the surgical and necropsy series

further that there is an excess of stage III tumours in the necropsy series.

The distribution of tumours of different cytological type in the two series is compared in table II.

\begin{tabular}{lll}
\hline $\begin{array}{l}\text { Cytological } \\
\text { Type }\end{array}$ & \multicolumn{2}{l}{ Series } \\
\cline { 2 - 3 } & Surgical & Necropsy \\
\hline I & 89 & 65 \\
II & 10 & 9 \\
III & 1 & 16 \\
\hline
\end{tabular}

Table II Percentage distribution of tumours of different cytological types in the surgical and necropsy series

In both the bulk of the material consists of type I tumours. The incidence of type II tumours is similar while type III tumours are overrepresented in the necropsy series.

The relationship of type I tumours in both series

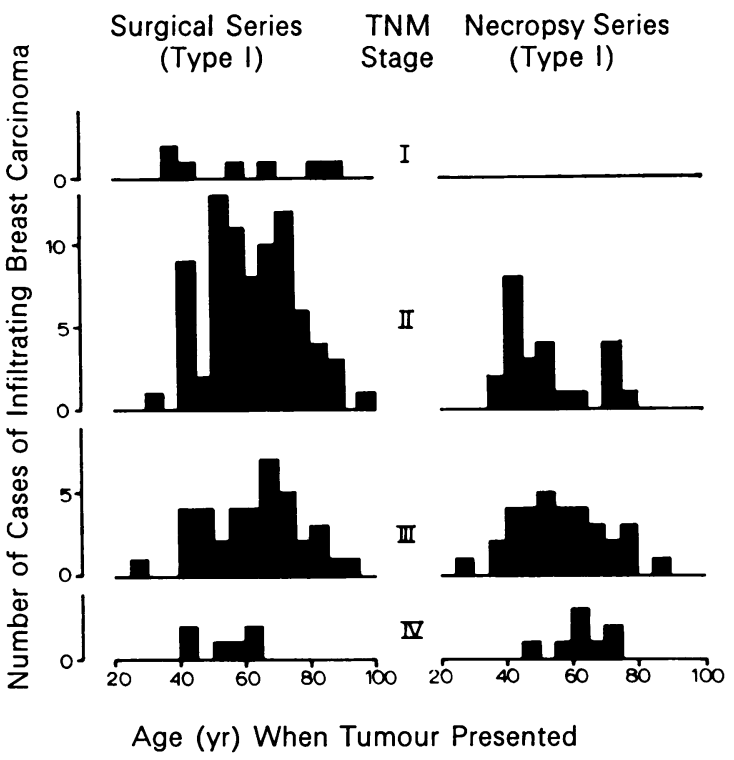

Fig 7 The relationship between TNM stage and age when the tumour presented for type I tumours in both the surgical and necropsy series.

to age and stage is shown in figure 7. The percentage distribution is very similar to that of the total series, except that there were no type I stage I tumours in the necropsy series. The excess of stage II tumours in the surgical series is again clear (61 to $37 \%$ ) and the excess of stage III tumours in the necropsy series (51 to $29 \%$ ).

The distribution of type II tumours related to age and TNM stage is given in fig 8 , and similar data for type III tumours in figure 9. (In these figures the histological type is also indicated by initials for reference.) Too few cases are present for analysis. Cases in which the histological typing was not consistent on two readings have been left blank.

In type II stages II, III, and IV are represented in the surgical series and II and III in the necropsy series. In type III there was only one case in the

\begin{tabular}{lll}
\hline $\begin{array}{l}\text { Histological } \\
\text { Type }\end{array}$ & Series & \\
\cline { 2 - 3 } & Surgical & Necropsy \\
\hline Duct & 35 & 11 \\
Scirrhous & 22 & 36 \\
Adenocarcinoma & 22 & 17 \\
Medullary & 8 & 23 \\
Colloid & 4 & 4 \\
Papillary & 9 & 9
\end{tabular}

Table III Percentage distribution of histological types within cytological type $I^{1}$

${ }^{1}$ Only consistent diagnoses were used. For details of numbers and staging see figure 10 . 


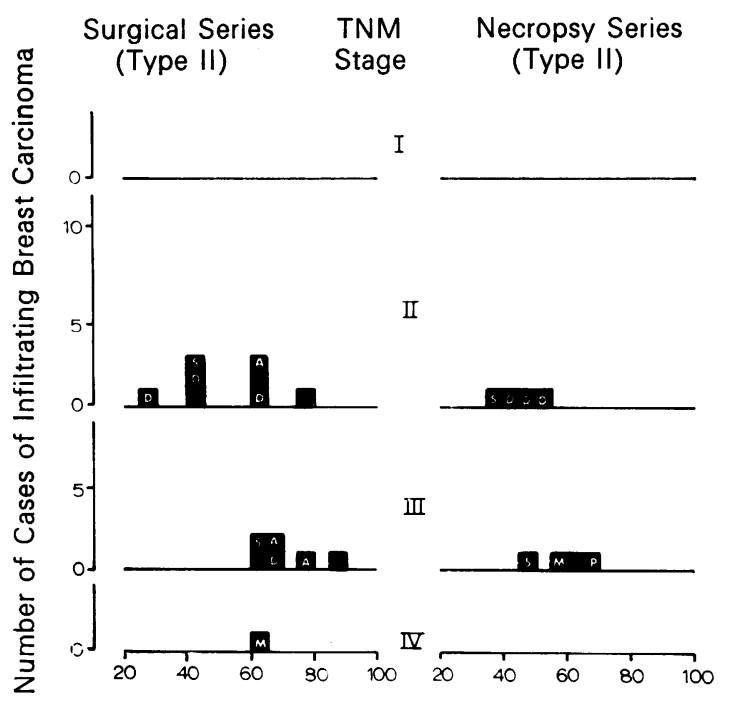

Age (yr) When Tumour Presented

Fig 8 The relationship between TNM stage and age when the tumour presented for type II tumours in the surgical and necropsy series.

surgical material, a stage II duct carcinoma occurring in an 80-year-old patient. Type III duct, scirrhous, and adenocarcinomas were found in the necropsy series.

The percentage distribution of the histological types within cytological type I is shown in table III. Only cases in which consistent histological readings were obtained are used in both series. There is an excess of duct carcinoma in the surgical as opposed to the necropsy series, a possible excess of scirrhous and a marked excess of medullary carcinoma in the necropsy series.

The distribution of the histological type within cytological type I related to age and TNM stage is shown in figure 10. No type I stage I tumours

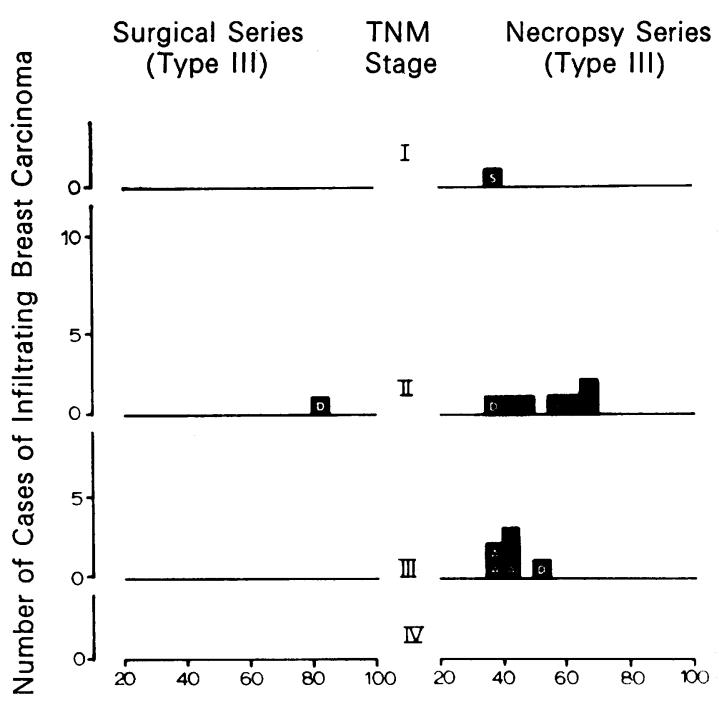

Age (yr) When Tumour Presented

Fig 9 The relationship between TNM stage and age when the tumour presented for type III tumours in the surgical and necropsy series.

occurred in the necropsy series, and no stage $\frac{1}{6}$ duct carcinomas, although both were represente the latter well represented, in the surgical series The cases in the necropsy series, particularly the scirrhous carcinomas, tended to be in the younger age groups, apart from papillary carcinomas which were related to old age.

The survival time in the necropsy series is shown in table IV related to cytological type and TNM stage. Increase in survival time is present from cytological types I to III. The differences for all stages combined are statistically significant (I-II, ? $0.05>$ P $>0.02$; II-III, $0.01>$ P $>0.001$ ). The reduction in survival time from stage II to III to IV is significant for type $I(0.02>P>0.01)$ and all

\begin{tabular}{|c|c|c|c|c|}
\hline \multirow[t]{2}{*}{ Stage } & \multicolumn{4}{|c|}{ Cytological Type } \\
\hline & $I$ & II & III & All \\
\hline $\mathbf{I}$ & - & - & $\begin{array}{l}14 \\
\text { (1) }\end{array}$ & $\begin{array}{l}14 \\
\text { (1) }\end{array}$ \\
\hline II & $\begin{array}{l}2.9 \pm 1.9 \\
(24)^{1}\end{array}$ & $\begin{array}{l}5 \cdot 2 \pm 2 \cdot 5 \\
\text { (4) }\end{array}$ & $\begin{array}{l}12 \cdot 2 \pm 3 \cdot 3 \\
\text { (7) }\end{array}$ & $\begin{array}{l}5.5 \pm 4 \cdot 5 \\
(35)\end{array}$ \\
\hline III & $\begin{array}{l}1.8 \pm 1.5 \\
(33)\end{array}$ & $\begin{array}{l}2.7 \pm 1.5 \\
\text { (4) }\end{array}$ & $\begin{array}{l}10 \cdot 0 \pm 3 \cdot 6 \\
(6)\end{array}$ & $\begin{array}{l}3.0 \pm 3.6 \\
(43)\end{array}$ \\
\hline IV & $\begin{array}{l}0.9 \\
(8)\end{array}$ & - & - & $\begin{array}{l}0.9 \\
(8)\end{array} \pm 0.8$ \\
\hline All & $\begin{array}{l}2 \cdot 1 \pm 1.8 \\
(65)\end{array}$ & $\begin{array}{l}4 \cdot 0 \pm 2 \cdot 4 \\
(8)\end{array}$ & $\begin{array}{l}11 \cdot 3 \pm 3 \cdot 7 \\
(14)\end{array}$ & $\begin{array}{l}3 \cdot 8 \pm 4 \cdot 1 \\
(87)\end{array}$ \\
\hline
\end{tabular}

Table IV Survival time related to cytological type and TNM stage in necropsy series 


\begin{tabular}{|c|c|c|c|c|}
\hline \multirow[t]{2}{*}{ Stage } & \multicolumn{4}{|c|}{ Histological Type } \\
\hline & Duct & Scirrhous & Adenocarcinoma & Medullary \\
\hline I & - & - & - & - \\
\hline II & - & $\begin{array}{l}3 \cdot 7 \\
(6)^{2}\end{array}$ & $\begin{array}{l}3.0 \pm 1.4 \\
(5)\end{array}$ & $\begin{array}{l}2.6 \pm 1.8 \\
(6)\end{array}$ \\
\hline III & $\begin{array}{l}1 \cdot 5 \pm 0.6 \\
(5)\end{array}$ & $\begin{array}{l}1 \cdot 2 \pm 0.8 \\
(10)\end{array}$ & $\begin{array}{l}1 \cdot 2 \pm 0.6 \\
(3)\end{array}$ & $\begin{array}{l}2 \cdot 3 \\
(6)\end{array}$ \\
\hline IV & $\begin{array}{l}3 \\
\text { (1) }\end{array}$ & $\begin{array}{l}0 \cdot 5 \pm 0 \\
(3)\end{array}$ & - & - \\
\hline
\end{tabular}

Table V Survival time in cases of histological type I related to TNM stage in necropsy series

${ }^{1}$ Too few papillary and colloid for evaluation.

No. of cases in parentheses.

types combined $(0.01>P>0.001)$. The average survival time for all cases combined was $3 \cdot 8 \pm 4 \cdot 1$ years and $2 \cdot 1 \pm 1 \cdot 8$ for type $I$.

The survival time is related to histological type for type I tumours with consistent histology in table $\mathrm{V}$ which again stresses the absence of stage I tumours and stage II duct carcinomas. The reduction in survival time from stage II to III was significant for scirrhous and adenocarcinomas $(0.05>P>0.02)$ but not medullary. Too few papillary and colloid carcinomas were present for comparison.

Agreement as to cytological type was recorded in the surgical series by both of us independently in $90 \%$ of cases. Table VI shows the number of cases with agreement and with disagreement. When type I is taken as a whole agreement was reached in $94 \%$

\begin{tabular}{lcccc}
\hline $\begin{array}{l}\text { Observer } 1 \\
\text { (Hartveit) }\end{array}$ & \multicolumn{2}{l}{ Observer 2} & (Maehle) & Total \\
\cline { 2 - 4 } & $I$ & $I I$ & III & \\
\hline I & $126^{2}$ & 4 & 0 & 130 \\
II & 9 & 6 & 1 & 16 \\
III & 0 & 0 & 1 & 1 \\
Total & 135 & 10 & 2 & 147 \\
\hline
\end{tabular}

Table VI Agreement and disagreement as to cytological type between two observers in the surgical series

${ }^{1}$ Agreement in italics of cases. The percentage agreement between two readings of histological type by one observer $(\mathrm{H}$. is shown in table VII. Agreement was reached in $78 \%$ of cases. The percentage agreement tended to be consistent for histological type, regardless of cytological type or series. Disregarding the few colloid and papillary tumours, agreement was better with duct and adenocarcinomas than with scirrhous carcinomas $(63 \%)$, while medullary came between these groups.

\section{Discussion}

The assessment of different methods of treatment of infiltrating breast cancer has long been hampered by the scatter in survival time that is to be expected. This is due to the great differences in life history that occur from tumour to tumour (Bloom, 1968). For this reason five-year survival rates underestimate the mortality. Ten years at least are required before an approximately reliable picture emerges (Bloom and Richardson, 1957). Even then the odd case will still turn up with a late recurrence. This has made long-term follow up essential in breast cancer series and hence the assessment of different methods of treatment cumbersome. The recognition of different cytological types of infiltrating breast carcinoma (Hartveit, 1971) may have simplified the

\begin{tabular}{|c|c|c|c|c|c|c|}
\hline \multirow{3}{*}{$\begin{array}{l}\text { Histological } \\
\text { Type }\end{array}$} & \multirow{2}{*}{$\begin{array}{l}\begin{array}{l}\text { Surgical } \\
\text { Series }\end{array} \\
\end{array}$} & \multirow{3}{*}{$\begin{array}{l}\text { Necropsy } \\
\text { Series }\end{array}$} & \multicolumn{4}{|l|}{ Both Series } \\
\hline & & & \multicolumn{4}{|c|}{ Cytological Type } \\
\hline & All Cytological Types & & $I$ & II & III & All \\
\hline $\begin{array}{l}\text { Duct } \\
\text { Scirrhous } \\
\text { Adenocarcinoma } \\
\text { Medullary } \\
\text { Colloid } \\
\text { Papillary }\end{array}$ & $\begin{array}{c}83(40 / 48) \\
62(24 / 39) \\
83(25 / 30) \\
60(9 / 15) \\
100(4 / 4) \\
82(9 / 11)\end{array}$ & $\begin{array}{c}93(14 / 15) \\
65(24 / 37) \\
93(13 / 14) \\
100(13 / 13) \\
100(2 / 2) \\
100(6 / 6)\end{array}$ & $\begin{array}{c}84(41 / 49) \\
64(41 / 64) \\
84(32 / 38) \\
87(20 / 23) \\
100(6 / 6) \\
88(14 / 16)\end{array}$ & $\begin{array}{c}88(7 / 8) \\
67(4 / 6) \\
100(3 / 3) \\
40(2 / 5) \\
-100(1 / 1)\end{array}$ & $\begin{array}{l}100(6 / 6) \\
50(3 / 6) \\
100(3 / 3) \\
- \\
- \\
-\end{array}$ & $\begin{array}{r}85 \\
63 \\
86 \\
78 \\
100 \\
94\end{array}$ \\
\hline All & 76 & 83 & 79 & 74 & 80 & 78 \\
\hline
\end{tabular}

Table VII Percentage consistent histological diagnosis in the two series related to cytological type 
$\begin{array}{ll}\text { Surgical Series } & \begin{array}{c}\text { TNM } \\ \text { Stage }\end{array} \quad \text { Necropsy Series }\end{array}$

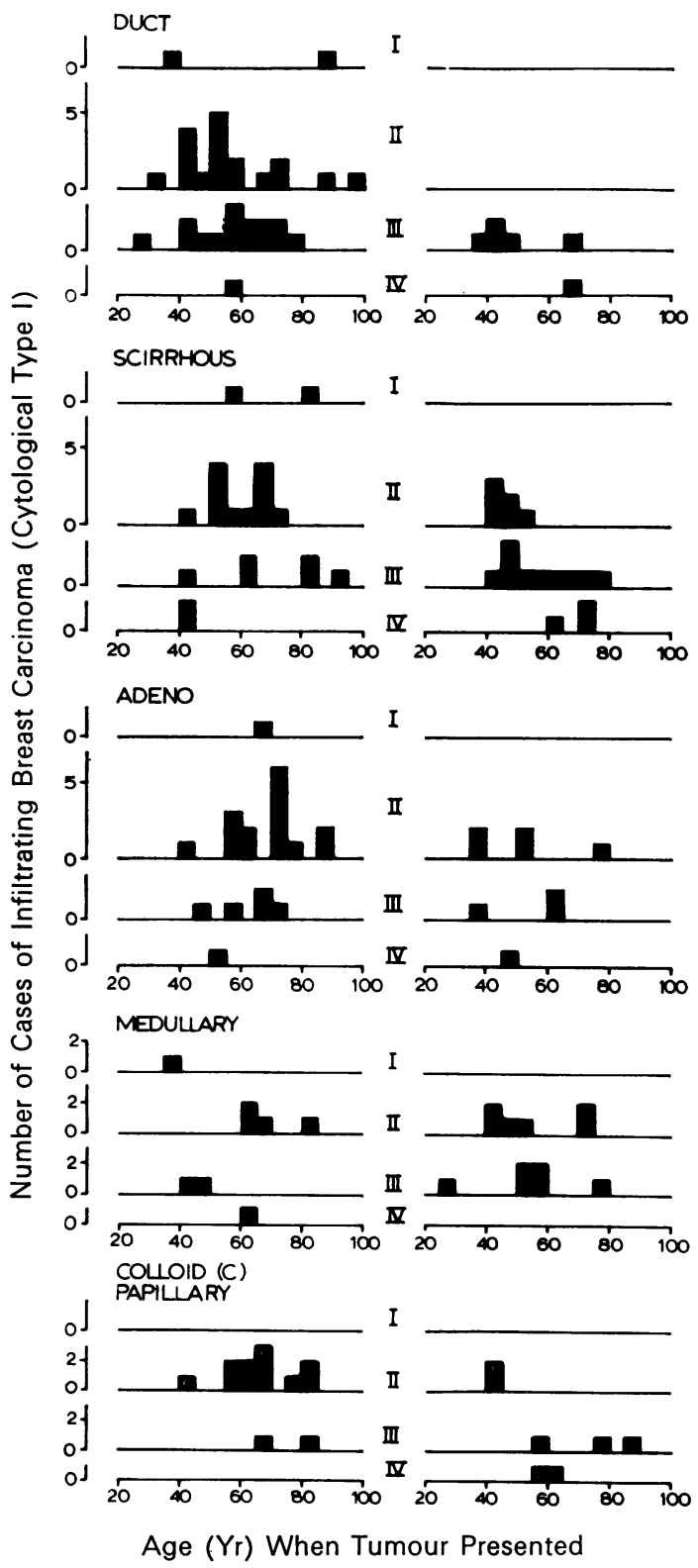

Fig 10 The distribution of histological types within cytological type I related to age and TNM stage in both surgical and necropsy series.

problem, as the patients who can expect to survive more than five years (type III) can now be picked out at operation.
The incidence of type III tumours (scirrhous, 0 duct, and adenocarcinoma) was under $1 \%$ in the present biopsy series compared with $16 \%$ in the necropsy series. Such tumours are thus rare. Their $\overrightarrow{\vec{*}}$ greater frequency in the necropsy series indicatesthat their ultimate prognosis is bad, although their short-term prognosis is good. Type II tumours $\overline{\overline{\bar{c}}}$. occurred with equal frequency in the two series $\bar{D}$ (10 and $9 \%$ ). Their survival time was intermediate between types I and III. Staging did not give $e^{\infty}$ further differentiation of the survival time in these $\overrightarrow{0}$ few cases.

The finding that type I tumours predominate in $\vec{\omega}$ the biopsy series, if confirmed from other centres ${ }^{1}, \widehat{\circ}$ will make it possible to assess treatment on these patients alone. If such patients die of their tumourso the necropsy series indicates that they do so within $\vec{\circ}$ a few years, irrespective of TNM stage, with the exception of stage I which was not found in the ${ }^{+}$ necropsy series. Thus five-year survival rates can be expected to give meaningful information about ${ }^{-}$ these type I tumours.

Differentiation as to histological type was nu-0 merically possible with type I. No significant differences in survival time related to histologicaltype were demonstrated in the necropsy serios within the different TNM stages. However, not oll. patients with type I tumours die of breast cancer:; in other words the possibility of surgical cure shoud s not be forgotten.

On comparison with the necropsy series itoำ appeared that there was a possible overrepresentation $\propto$ of type 1 duct carcinomas in the biopsy series. $\overrightarrow{\vec{A}}$ Further analysis showed that this was due mainly 3 to stage II tumours, which accounted for $17 \%$ of the surgical material, while none were found in the necropsy series. Due mainly to these duct carcinomas, stage II tumours as a whole were better represented? in the surgical material than stage III, while the 3 opposite was true for the necropsy series. This suggests that the possibility of cure, as opposed to윽 a prolonged survival time, may be better in type $I_{O}$ stage II duct carcinomas than in the other histologi- cal types.

In contrast stage II and III medullary type Iㅡ. tumours were overrepresented in the necropsy series, suggesting that the possibility of cure may be lower here, though the number of cases involved is small too. In addition the difference in survival $\omega$ time between stages II and III was not significant in contrast to scirrhous and adenocarcinomas in 0 which the survival time was significantly less in stage III than in stage II.

Although only cases in which a consistent histological diagnosis was reached were used in these $\frac{\overrightarrow{0}}{\mathrm{P}}$ 'See addendum 
comparisons it should be remembered that such classification is subjective and carries different degrees of error within the different histological types, for example, $86 \%$ agreement on two readings for duct compared to $63 \%$ for scirrhous carcinoma in the present series.

Schiødt (1966) concluded that histological classification is of no prognostic value in other than colloid and medullary carcinoma (10\% of his material.) His use of the method, however, implies that such classification was regarded as consistent enough to justify the conclusion. It is well known that most breast carcinomas will show variation in histological pattern within the same slide. Preliminary studies on a group of tumours indicate that this variation may not increase from block to block in the same tumour.

The TNM staging showed up differences in survival time within cytological type $I$ and in the necropsy series as a whole, but not in types II and III separately. Significant differences in survival time related to stage were also found in type I scirrhous and adenocarcinomas but not in medullary carcinomas. It is thus possible that to obtain the greatest use of TNM staging for the comparison of treatment results in tumours of different stages the basic material should be confined to type I tumours of similar histological type.

This work was carried out with the technical help of Miss S. Heieren financed by the Norwegian Cancer Society.

\section{References}

Bloom, H. J. G. (1968). Survival of women with untreated breast cancer-past and present. In Prognostic Factors in Breast Cancer: Proceedings of the first Tenovus Symposium, Cardiff, April, 1967, edited by A. P. M. Forrest and P. B. Kunkler, pp. 3-19. Livingstone, Edinburgh and London.

Bloom, H. J. G., and Richardson, W. W. (1957). Histological grading and prognosis in breast cancer. Brit. J. Cancer, 11, 359-377.
Collins, V. P. (1956). Breast cancer: the influence of treatment that fails to cure. Cancer (Philad.), 9, 1177-1181.

Daland, E. M. (1927). Untreated cancer of the breast. Surg. Gynec. Obstet., 44, 264-268.

Harmer, M., Denoix, P., and Hamperl, H. (1970). The TNM-system In Surgical Oncology (Current Problems in Surgery), edited by F. Saegesser and J. Pettavel, pp. 25-36. Huber, Bern, Stuttgart, Vienna.

Hartveit, F. (1971). Prognostic typing in breast cancer. Brit. med. J., 4, 253-257.

Norway Central Bureau of Statistics (1969). Causes of Death, 1969, pp. 38-39. Oslo.

Prutting, J. (1972). The autopsy. (Letter). J. Amer. med. Ass., 222, $1556-1557$.

Ringertz, N. (1971). Cancer incidence in Finland, Iceland, Norway, and Sweden: a comparative study by the Cancer Registries. Acta path. microbiol. scand., [A], Suppl., 224, 48-49.

Schiødt, T. (1966). Breast Carcinoma: A Histologic and Prognostic Study of 650 Followed-up Cases. Munksgaard, Copenhagen.

\section{Addendum}

Since this paper was completed a report (Turner, D. R. and Berry, C. L., J. clin. Path., 1972, 25, 10531055) has appeared in which the typing system of Bloom and Richardson is compared with the cytological typing system used in the present work to the detriment of the latter. The authors compare the incidence of the different cytological types in two groups of patients. In those dying within five years of radical mastectomy their figures, $83 \%$ type I, $17 \%$ type II, $0 \%$ type III, are consistent with those previously reported (Hartveit, 1971). They also confirm the predominance of type I tumours, the rarity of type III tumours, and do not seem to have had difficulty in using the typing criteria. Discrepancy, however, appears to arise among their 'long-term survivors' which include $46 \%$ patients with type I tumours. However, as these 'comprised 80 patients surviving 10 years after radical mastectomy such a finding is not unexpected. The previously quoted series was based on patients dying of breast cancer more than 10 years after removal of the primary. 